\title{
óleo essencial de orégano, alecrim, canela e extrato de pimenta no controle de Salmonella, Eimeria e Clostridium em frangos de corte ${ }^{1}$
}

\author{
Tânia D.M.M. Bona², Larissa Pickler²*, Leonardo B. Miglino², Leandro N. Kuritza², \\ Sâmara P. Vasconcelos ${ }^{2}$ e Elizabeth Santin
}

\begin{abstract}
Bona T.D.M.M., Pickler L., Miglino L.B., Kuritza L.N., Vasconcelos S.P. \& Santin E. 2012. [Oregano, rosemery, cinnamon essential oil and pepper extract to control Salmonella, Eimeria and Clostridium in broiler chickens.] Óleo essencial de orégano, alecrim, canela e extrato de pimenta no controle de Salmonella, Eimeria e Clostridium em frangos de corte. Pesquisa Veterinária Brasileira 32(5):411-418. Laboratório de Microbiologia e Ornitopatologia, Departamento de Medicina Veterinária, Universidade Federal do Paraná, Rua dos Funcionários 1540, Curitiba, PR 80035-050, Brasil. E-mail: larissapickler@yahoo.com.br

The efficiency of a product in broiler feed containing essential oil of oregano, rosemary, cinnamon and extract of red pepper (plant compost) in the control of Salmonella, Eimeria and Clostridium was evaluated. Two experiments were carried out to evaluate the product. In the first experiment the efficiency of this product to control Clostridium perfringens after challenge with Eimeria acervulina, E. maxima and E. tenella was assessed. Day old chicks were allotted into three groups: T1 - control diet without growth promoter, T2 - diet with avilamycin (10ppm), and T3 - diet with addition of the plant compost (100ppm). The use of the plant compost in broiler diets reduced specific lesions of E. maxima and E. tenella at 14 days after inoculation and reduced the count of colony forming units (CFU) of Clostridium perfringens in the ceca comparing to the control group. In the second trial the efficiency of the same product in birds challenged with Salmonella Enteritidis was evaluated. Day old birds were submitted to three experimental diets: T1 - control diet without antibiotics growth promoter, T2 - diet with 10ppm Avilamycin, T3 - diet with 100ppm of the plant compost mentioned above. At 21 days of age all birds were inoculated with $10^{5} \mathrm{CFU}$ of Salmonella Enteritidis. The use of the plant compost and avilamycin decreased the excretion of Salmonella in poultry 72 hours after the inoculation. The use of the plant compost increased villous $/ \mathrm{CD}^{+}$cells in the duodenum, compared to group avilamycin and control, but had no effect on the expression of these cells in the cecum.
\end{abstract}

INDEX TERMS: CD3+ cells, coccidiosis, plant extracts, essential oils.

RESUMO.- Este trabalho foi conduzido com o objetivo de avaliar a eficiência de um composto vegetal contendo óleo essencial de orégano, alecrim, canela e extrato de pimenta vermelha no controle de Salmonella, Eimeria e Clostridium em frangos de corte. Para tal, foram realizados dois experi-

\footnotetext{
${ }^{1}$ Recebido em 17 de setembro de 2011.

Aceito para publicação em 24 de janeiro de 2012.

${ }^{2}$ Laboratório de Microbiologia e Ornitopatologia, Departamento de Medicina Veterinária, Universidade Federal do Paraná, Rua dos Funcionários 1540, Curitiba, PR 80035-050, Brasil. *Autor para correspondência: larissapickler@yahoo.com.br
}

mentos. No primeiro avaliou-se a eficiência deste produto no controle de Clostridium perfringens após desafio com Eimeria acervulina, E. maxima e E. tenella. Aves de um dia de idade foram divididas em três grupos: T1 - dieta controle sem aditivo promotor de crescimento; $\mathrm{T} 2$ - dieta com adição de avilamicina (10ppm); e T3 - dieta com adição do composto vegetal $(100 \mathrm{ppm})$. O uso do composto vegetal na alimentação de frangos reduziu lesões específicas de $E$. maxima e E. tenella aos 14 dias pós-inoculação (PI) como também reduziram a contagem de unidades formadoras de colônias (UFC) de Clostridium perfringens no conteúdo do ceco das aves em relação ao grupo controle. No segundo 
experimento avaliou-se a eficiência deste mesmo produto em aves desafiadas com Salmonella Enteritidis. Aves de um dia de idade foram distribuídas em três tratamentos, sendo T1 - dieta controle sem adição de antibiótico promotor de crescimento, T2 - dieta com 10ppm de Avilamicina, T3 - dieta com 100ppm de um produto a base do composto vegetal acima citado. Aos 21 dias de idade todas as aves foram inoculadas com $10^{5}$ UFC de Salmonella Enteritidis. A utilização do composto vegetal e avilamicina diminuiu a excreção de Salmonella nas aves 72 horas PI de Salmonella. A utilização do composto vegetal aumentou a relação vilo/ células $\mathrm{CD}^{+}$no duodeno, em relação ao grupo avilamicina e controle, porém não teve efeito sobre a expressão destas células no ceco.

TERMOS PARA INDEXAÇÃO: Células CD3+, coccidiose, extrato de plantas, óleos essenciais.

\section{INTRODUÇÃO}

Óleos essenciais constituem-se em complexas misturas de substâncias voláteis, geralmente lipofílicas (Simões \& Spitzer 1999), cujos componentes incluem hidrocarbonetos terpênicos, álcoois simples, aldeídos, cetonas, fenóis, ésteres, ácidos orgânicos fixos, etc, em diferentes concentrações, nos quais, um composto farmacologicamente ativo é majoritário. No orégano, este composto é o carvacrol (3-17\%); e, na canela, o cinamaldeído (75\%) (Farmacopea Italiana 1998).

Como mecanismo de ação dos óleos essenciais acredita-se que a maioria deles exerce efeito antimicrobiano na estrutura da parede celular bacteriana, desnaturando e coagulando proteínas. Alteram a permeabilidade da membrana citoplasmática para íons de hidrogênio e potássio, causando a interrupção dos processos vitais da célula, como transporte de elétrons, translocação de proteínas, fosforilação e outras reações que dependem de enzimas, o que resulta em perda do controle quimiosmótico da célula afetada, levando a morte bacteriana (Dorman \& Deans 2000).

A coccidiose é uma das doenças aviárias causada por protozoários do gênero Eimeria, presente em praticamente todos os plantéis avícolas. Causa prejuízos, tanto pelo aumento da conversão alimentar, diminuição na taxa de crescimento e, às vezes, por aumentar a mortalidade nos lotes (Mc Dougald 1998), quanto por ser também um fator predisponente ao surgimento de clostridiose, por danificar os tecidos intestinais e modificar as funções do trato gastrointestinal quebrando as barreiras naturais de defesa do animal (Gil de los Santos et al. 2008). As principais eimérias que causam problemas em avicultura são a Eimeria acervulina que provoca principalmente lesões em duodeno, a $E$. maxima que causa lesões em jejuno e íleo e a $E$. tenella que causa processos hemorrágicos no ceco das aves. Embora o uso de anticoccidianos seja eficiente no controle da doença o aparecimento de resistência limita seu uso na eliminação da doença em granjas comerciais, em vista disso estudam-se alternativas para o controle desta enfermidade, como óleos essenciais e extratos vegetais. Christaki et al. (2004) obtiveram resultados positivos com relação ao desempe- nho zootécnico (ganho de peso, consumo de ração e conversão alimentar) além de observarem uma redução nas lesões em ceco dos animais tratados com mistura comercial de óleos essenciais em frangos desafiados com Eimeria tenella.

Clostridium perfringens participa da microbiota intestinal normal de frangos, porém, alguns fatores como mudanças bruscas na alimentação, stress, salmoneloses, micotoxinas e coccidiose fazem em com que este micro-organismo reproduza-se rapidamente produzindo toxinas que causam lesões ulcerativas e necrose da mucosa intestinal levando a uma doença conhecida como enterite necrótica (Saif 2008). Estima-se que esta doença possa causar perdas da ordem de até $33 \%$ nos plantéis avícolas devido aos gastos com medicamentos, redução no ganho de peso e aumento da conversão alimentar (Lovland \& Kaldhusdal 2001). A capsaicina, o cinamaldeído e o carvacrol podem reduzir o número de $C$. perfringens em ceco de frangos (Jamroz \& Kamel 2002), bem como uma mistura de óleos essenciais a base de carvacrol, timol, cinamaldeído, eugenol e capsaicina reduziu a contagem desta bactéria em duodeno, jejuno, íleo e ceco de frangos (Mitsch et al. 2004).

A salmonelose é uma zoonose de importância mundial que preocupa as autoridades sanitárias e se constitui em importante barreira ao comércio internacional de alimentos. A ampla distribuição de Salmonella entre os animais e sua capacidade de sobreviver por longos períodos no meio ambiente contribuem para seu destacado papel em saúde pública (Butaye et al. 2003). 0 gênero Salmonella pertence à família Enterobacteriaceae e compreende as espécies $S$. enterica e $S$. bongori; a espécie $S$. enterica alberga as linhagens patogênicas distribuídas em seis subespécies e 2.564 sorovares, todas patogênicas ao homem (Bopp et al. 2003) onde inclue-se a Salmonella Enteritidis (SE).

Neste contexto, aumenta a importância da exploração do potencial antimicrobiano, bem como de outras propriedades, das plantas e de seus respectivos constituintes. Este trabalho foi dividido em dois experimentos sendo que o primeiro teve como objetivo avaliar a eficiência de óleo essencial de orégano, alecrim, canela e extrato pimenta vermelha, no controle da coccidiose e de Clostridium perfringens em frangos desafiados com Eimeria acervulina, $E$. maxima e E. tenella e o segundo experimento teve o objetivo de avaliar a eficiência antimicrobiana deste mesmo produto em aves desafiadas com Salmonella Enteritidis, além de avaliar a morfometria intestinal e a presença de células $\mathrm{CD}^{+}$(linfócitos T) na mucosa intestinal.

\section{MATERIAL E MÉTODOS}

\section{Experimento 1}

Foram alojadas 51 frangos de corte linhagem Cobb $500^{\circledR}$ de um dia de idade em cama de maravalha, divididas em três grupos sendo 17 animais por tratamento. Cada tratamento recebeu ração formulada de acordo com os níveis recomendados pelo NRC (1994) sem adição de coccidiostático, sendo que o T1 recebeu dieta controle sem adição de antibiótico promotor de crescimento (APC), T2 dieta com adição de 10ppm de avilamicina, e T3 dieta com adição de $100 \mathrm{ppm}$ de composto vegetal sendo uma mistura comercial a base de óleos essenciais de orégano (carvacrol), alecrim (cineol), canela (cinamaldeído) e extrato de pimenta verme- 
lha (capsaicina). Os níveis dos produtos adicionados nas rações seguiram as recomendações dos fabricantes. Cada dieta foi fornecida do primeiro ao último dia do experimento.

0 composto vegetal possui óleo essencial de orégano (Origanum vulgare), canela (Cinnamomum zeylanicum) e alecrim (Rosmarinus officinallis) e extrato de pimenta vermelha (Capsicum annuum) e apresenta garantias mínimas de $4,5 \mathrm{mg} / \mathrm{kg}$ de carvacrol, $1,0 \mathrm{~g} / \mathrm{kg}$ de cinamaldeído, $2,0 \mathrm{~g} / \mathrm{kg}$ de cineol e $20 \mathrm{~g} / \mathrm{kg}$ de capsaicina. De acordo com o FDA (Code of Federal Regulations 21 CFR 172.515, 2008; 21 CFR 582.10, 2001) estas matérias primas são consideradas seguras e inócuas para animais e seres humanos.

Foi realizada necropsia de cinco aves por tratamento aos nove dias de idade para coleta de fragmentos de fígado sendo fixado em solução formalina tamponada a $10 \%$. As amostras foram processadas e coradas com Hematoxilina e Eosina (HE) para análise histológica utilizando microscópio óptico.

Aos 15 dias de idade os animais receberam 1,8mL de inóculo por via oral, com seringa acoplada em sonda, com pool de oocistos esporulados de Eimeria acervulina $\left(200 \times 10^{3}\right)$, E. maxima $\left(50 \times 10^{3}\right)$ e E. tenella $\left(10 \times 10^{3}\right)$. Os oocistos foram obtidos de cepas de campo replicados de acordo com Costa \& Paiva (2007).

Aos 22 e 29 dias de idade (7 e 14 dias pós -inoculação), foi realizada a eutanásia e necropsia de 36 aves, sendo 18 aos 22 dias e 18 aos 29 dias de idade (seis aves por tratamento) para avaliação intestinal de lesões de coccidiose e enterites inespecíficas. As lesões de coccidiose foram avaliadas segundo os escores de lesão definidos por Johnson \& Reid (1970) (Grau 0 - sem lesão; Grau 1 - lesão leve; Grau 2 - lesão moderada; Grau 3 - lesão severa; Grau 4 - lesão muito severa), e as lesões de enterites inespecíficas foram classificadas em escores de acordo com Saad (2009) (Grau 0 - sem lesão; Grau 1 - lesão leve; Grau 2 - lesão moderada; Grau 3 - lesão severa).

Na segunda coleta, 14 dias pós-inoculação, também foram coletados conteúdo cecal para contagem de Clostriduim perfringens.

Para o procedimento de contagem de Clostridium perfringens foi adicionado 1,0g de conteúdo cecal em $9 \mathrm{~mL}$ de solução fisiológica estéril, desta diluição retirou-se $1 \mathrm{~mL}$ sendo pipetado em um tubo com 9,0mL de solução fisiológica estéril e assim sucessivamente até a diluição $10^{-4}$. Retirou-se $100 \mu \mathrm{L}$ de cada diluição e foi espalhado em placas de Reinforced Clostridium Agar (Himedia ${ }^{\circledR}$ ) enriquecido com sangue de carneiro em duplicata. As placas foram incubadas em jarra de anaerobiose $\left(\right.$ Oxoid $\left.^{\circledR}\right)$ e levadas a estufa regulada a $35^{\circ} \mathrm{C}$ por 24 horas. Foi verificado o crescimento de colônias típicas de Clostridium perfringens que apresentavam um halo de beta-hemólise sendo confirmadas pela coloração de Gram. Posteriormente, as colônias foram contadas e os resultados foram expressos de acordo com Procedimentos de Contagem de Colônia de acordo com a Normativa nำ publicada em 26 de agosto de 2003 (MAPA).

A contagem das colônias de Clostridium foi transformada em Log10 para converter os dados em distribuição normal para realização da análise estatística. A contagem de colônias de Clostridium e escores de lesão foram analisados no programa StatView for Windows Copyright ${ }^{\odot} 1998$ (SAS Institute Inc., NC, USA) com ANOVA e teste de Post Hoc de Fischer com significância menor que 0,05 .

\section{Experimento 2}

Foram alojadas 24 frangos de corte linhagem Cobb $500^{\circledR}$ de um dia de idade, distribuídas em um desenho experimental inteiramente casualizado com três tratamentos e oito repetições, sendo cada ave uma repetição. Cada tratamento recebeu ração formulada de acordo com os níveis recomendados pelo NRC (1994) sem adição de coccidiostático, sendo que o T1 recebeu dieta controle sem adição de antibiótico promotor de crescimento, T2 dieta contendo 10ppm de Avilamicina, T3 dieta contendo 100ppm de composto vegetal sendo uma mistura comercial a base de óleos essenciais de orégano (carvacrol), alecrim (cineol), canela (cinamaldeído) e extrato de pimenta vermelha (capsaicina). Os níveis dos produtos adicionados nas rações seguiram as recomendações dos fabricantes. Cada dieta foi fornecida durante todos os dias do experimento. 0 composto vegetal adicionado na ração era o mesmo fornecido no primeiro experimento.

Aos 21 dias de idade todas as aves receberam 1,0mL de inóculo via oral contendo $10^{5} \mathrm{UFC} / \mathrm{mL}$ de SE, com o uso de seringa acoplada em sonda diretamente no esôfago das aves.

Swabs de cloaca de todos os animais foram coletados às 24,48 e 72 horas pós-inoculação e as amostras foram processadas para contagem de Salmonella.

Para o procedimento de contagem de Salmonella os swabs cloacais foram colocados em tubos contendo $2,0 \mathrm{~mL}$ de água peptonada $2 \%$. Foram retirados $1,0 \mathrm{~mL}$ desta solução e pipetados em tubo contendo $9,0 \mathrm{~mL}$ de água peptonada $0,1 \%$ (diluição $10^{-1}$ ) e assim sucessivamente até as diluições $10^{-2}$ e $10^{-3}$. Foi retirado $100 \mu \mathrm{L}$ de cada diluição e plaqueado em duplicata em meio Lisina Xilose Desoxicolato (XLD). As placas foram incubadas em estufa regulada a $35^{\circ} \mathrm{C}$ por $24 \mathrm{~h}$ para posterior contagem das colônias (adaptado de Desmidt et al. 1998). Os resultados foram expressos de acordo com Procedimentos de Contagem de Colônia de acordo com a Normativa no 62 publicada em 26 de agosto de 2003 (Brasil - MAPA).

Os tubos contendo os swabs e a água peptonada $2 \%$ foram incubados a $35^{\circ} \mathrm{C}$ por $24 \mathrm{~h}$. Quando não havia a presença de colônias típicas de Salmonella nas placas após $24 \mathrm{~h}$ de incubação, era retirado $100 \mu \mathrm{L}$ da solução de suabe em água peptonada $2 \%$ e acrescido em tubo contendo $10 \mathrm{~mL}$ de caldo Rappaport-Vassiliadis, sendo então incubado em estufa regulada a $42^{\circ} \mathrm{C}$ por $24 \mathrm{~h}$ para confirmação da presença ou ausência de Salmonella.

Aos 24 dias de vida das aves (terceiro dia após a inoculação) oito aves de cada tratamento foram eutanasiadas por deslocamento cervical e necropsiadas. Foram coletados fragmentos de duodeno, íleo e ceco, em solução formalina tamponada a $10 \%$, para avaliação histológica, morfométrica e imuno-histoquímica (duodeno e ceco).

As amostras de duodeno, íleo e ceco foram processadas e coradas com Hematoxilina e Eosina (HE) e Alcian Blue para análise histológica (Luna 1968). As variáveis estudadas nos intestinos foram altura dos vilos, profundidade das criptas, contagem de células caliciformes (coradas em azul), com leitura em aumento de 40x de 20 vilos e criptas em cada grupo experimental (adaptado de Maiorka et al. 2000). As análises morfométricas do epitélio intestinal foram feitas em microscopia de luz, em sistema analisador de imagens acoplado ao microscópio óptico. Após a obtenção dos dados, foi realizada a relação vilo/células caliciformes e vilo/ cripta.

Fragmentos de duodeno e ceco também foram coletados para realização de imuno-histoquímica. Para o procedimento de imuno-histoquímica foi realizada a recuperação antigênica colocando-se as amostras em solução Tampão Citrato pH 6,0 em microondas por 10 minutos. Na sequência, as amostras receberam anticorpo policlonal desenvolvido em coelhos como anticorpo primário anti-CD3 (DAKO Corporation, CA, USA), diluído 1:750, por 40 minutos em temperatura ambiente. Para detecção da reação foi utilizado anticorpos secundários anti-camundongo e anti-coelho combinados num mesmo sistema de amplificação (Kit ADVANCE ${ }^{\circledR}$ - DAKO Corporation, CA, USA) por 40 minutos em temperatura ambiente. Para revelação utilizou-se cromógeno (Kit DAB ${ }^{\circledR}$ - DAKO Corporation, CA, USA) por 5 minutos. A contra-coloração foi realizada com hematoxilina Meyer por um minuto. As análises imuno-histoquímicas dos intestinos foram 
feitas em microscopia de luz, em sistema analisador de imagens (Motic Images Plus 2.0-Motic China Group Co.2006), acoplado ao microscópio (Olympus BH2 Olympus America Inc., NY, USA). Nas amostras de duodeno e ceco foi realizada a quantificação de células CD3 positivas intra-epiteliais, em toda a extensão do vilo, sendo contado 10 vilos por tratamento. Foi realizada também a relação vilo/células $\mathrm{CD}^{+}$.

Todos os resultados obtidos foram analisados pelo programa estatístico StatView for Windows Copyright ${ }^{\circledR} 1998$ (SAS Institute Inc., NC, USA). A contagem de colônias foi transformada em Log 10 para diminuir a amplitude dos resultados. Os resultados da altura dos vilos, profundidade das criptas, relação vilo-cripta e contagem das células caliciformes foram submetidos à ANOVA $(P<005)$ e caso as médias obtidas apresentassem diferença significativa, essas eram submetidas ao teste de Tukey.

\section{RESULTADOS}

\section{Experimento 1}

No Quadro 1 estão apresentados os dados referentes a média e desvio padrão dos escores de lesão específica de coccidiose aos 22 dias de idade (sete dias após a inoculação), não havendo diferença significativa entre os tratamentos.

Não foram observadas diferenças significativas nas avaliações de enterites inespecíficas, tanto aos 22 quanto aos 29 dias de idade (7 e 14 dias pós-inoculação de eimérias). No Quadro 2 estão apresentados os dados referentes a média e desvio padrão dos escores de lesão específica de coccidiose aos 29 dias de idade (14 dias após a inoculação). Não foi observada diferença significativa para lesões de Eimeria acervulina entre os tratamentos. Entretanto, para lesões de E. maxima e E. tenella, as aves dos tratamentos com avilamicina e composto vegetal apresentaram significativa redução em severidade.

No Quadro 3 estão apresentados os dados referentes à contagem de colônias de Clostridium perfringens aos 29 dias de idade (14 dias após a inoculação de eimerias), mostrando que o grupo de aves alimentadas com dieta com avilamicina controlou significativamente a contagem de

Quadro 1. Média e Desvio padrão de escores de lesões específicas de coccidioses no trato gastrintestinal observadas na necropsia aos 22 dias de idade (sete dias após a inoculação de eimerias)

\begin{tabular}{|c|c|c|c|c|}
\hline Eimeria sp. & Controle & Avilamicina & Composto vegetal* & Valor de P \\
\hline E. acervulina & $0,60 \pm 0,90$ & $0,40 \pm 0,55$ & $1,40 \pm 1,34$ & 0,2918 \\
\hline E. maxima & $0,40 \pm 0,90$ & $0,40 \pm 0,90$ & $1,40 \pm 1,34$ & 0,3814 \\
\hline E. tenella & $2,00 \pm 1,00$ & $2,20 \pm 0,84$ & $1,20 \pm 0,84$ & 0,2917 \\
\hline
\end{tabular}

* Composto vegetal - óleo essencial de orégano, alecrim, canela e extrato de pimenta vermelha.

Quadro 2. Média e Desvio padrão de escores de lesões específicas de coccidiose no trato gastrintestinal observadas na necropsia aos 29 dias de idade (14 dias após a inoculação de eimerias)

\begin{tabular}{lcccc}
\hline \multicolumn{1}{c}{ Eimeria sp. } & Controle & Avilamicina & Composto vegetal* & Valor de P \\
\hline E. acervulina & $1,00 \pm 0,90$ & $0,50 \pm 0,84$ & $0,17 \pm 0,40$ & 0,2607 \\
E. máxima & $0,83 \pm 0,98^{\mathrm{a}^{* *}}$ & $0,00 \pm 0,00^{\mathrm{b}}$ & $0,00 \pm 0,00^{\mathrm{b}}$ & 0,033 \\
E. tenella & $0,83 \pm 0,41^{\mathrm{a}}$ & $0,33 \pm 0,52^{\mathrm{b}}$ & $0,00 \pm 0,00^{\mathrm{b}}$ & 0,006
\end{tabular}

* Composto vegetal - óleo essencial de orégano, alecrim, canela e extrato de pimenta vermelha.

** Letras diferentes na mesma linha diferem estatisticamente $(\mathrm{P}<0,05)$.
Quadro 3. Média dos resultados de contagem de colônias de Clostridium perfringens ( Log10 UFC/g) de conteúdo cecal aos 29 dias de idade (14 dias após a inoculação de eimérias) $(P<0,0001)$

\begin{tabular}{lc}
\hline \multicolumn{1}{c}{ Tratamento } & $\log 10 \mathrm{UFC} / \mathrm{g}$ \\
\hline Controle & $10 \times 10^{8 \mathrm{a}^{* *}}$ \\
Avilamicina & $0^{\mathrm{b}}$ \\
Composto vegetal* $^{*}$ & $2,7 \times 10^{8 \mathrm{c}}$
\end{tabular}

* Composto vegetal - óleo essencial de orégano, alecrim, canela e extrato de pimenta vermelha.

** Letras diferentes na mesma coluna diferem estatisticamente $(\mathrm{P}<0,05)$.

Clostridium perfringens, enquanto que o grupo tratado com o composto vegetal apresentou redução significativa deste microrganismo em relação ao grupo controle.

\section{Experimento 2}

Na contagem de colônias de Salmonella após coleta de suabe de cloaca de aves de 21 dias de idade inoculadas com $10^{5} \mathrm{UFC} / \mathrm{mL}$ de Salmonella Enteritidis (SE), foi observada significativa diferença 24 e 72 horas após a inoculação (Quadro 4). Nas primeiras 24 horas, o grupo que recebeu avilamicina na dieta apresentou contagem significativamente menor em relação ao grupo controle e ao grupo que recebeu o composto vegetal. Entretanto, 72 horas após a inoculação, tanto o grupo que recebeu avilamicina na dieta quanto o que recebeu o composto vegetal obtiveram contagem significativamente inferior ao grupo controle.

Quadro 4. Contagem de colônias de Salmonella observadas em swabs de cloaca de aves de 21 dias de idade inoculadas com $10^{5}$ UFC de Salmonella Enteritidis 24, 48 e 72 horas após a inoculação (PI) (Média \pm Desvio Padrão dos valores expressos em Log 10)

\begin{tabular}{ccccc}
\hline Horas PI & Controle & Avilamicina & Composto vegetal* & Valor de P \\
\hline 24 horas & $3,68 \pm 0,90^{\mathrm{a}^{* *}}$ & $0,77 \pm 1,55^{\mathrm{b}}$ & $2,48 \pm 1,70^{\mathrm{a}}$ & 0,051 \\
48 horas & $0,91 \pm 1,34$ & $0,00 \pm 0,00$ & $1,50 \pm 1,73$ & 0,298 \\
72 horas & $4,15 \pm 0,89^{\mathrm{a}}$ & $1,70 \pm 1,96^{\mathrm{b}}$ & $1,19 \pm 1,49^{\mathrm{b}}$ & 0,047 \\
\hline
\end{tabular}

* Composto vegetal - óleo essencial de orégano, alecrim, canela e extrato de pimenta vermelha.

** Letras diferentes na mesma linha diferem estatisticamente $(\mathrm{P}<0,05)$.

$\mathrm{Na}$ avaliação histológica de duodeno (Quadro 5), foi observado altura de vilo significativamente maior no grupo alimentado com composto vegetal em relação ao controle, sendo similar ao grupo avilamicina. 0 número de células caliciformes também foi significativamente maior, inclusive em relação ao grupo avilamicina, sendo confirmado pela menor relação vilo/células caliciformes. Não houve diferença significativa de profundidade de criptas entre os tratamentos. Entretanto, ao realizar a relação vilo/cripta, observou-se maior relação no grupo composto vegetal. Em relação à imuno-histoquímica, foi observado contagem significativamente maior de células $\mathrm{CD}^{+}$no grupo que recebeu dieta com avilamicina em relação ao grupo composto vegetal. Porém ao ser realizada a relação vilo/células $\mathrm{CD}^{+}$, observou-se incremento significativo para a proporção no grupo composto vegetal em relação ao grupo controle e 
Quadro 5. Avaliações em microscopia ótica de fragmentos de duodeno de aves de 24 dias de idade inoculadas com $10^{5}$ UFC Salmonella Enteritidis (Média \pm Desvio Padrão)

\begin{tabular}{|c|c|c|c|c|}
\hline Variáveis & Controle & Avilamicina & Composto vegetal* & Valor de P \\
\hline Vilosidade $(\mu \mathrm{m})$ & $580,25 \pm 145,18 \mathrm{a}^{\mathrm{a}^{* *}}$ & $648,91 \pm 141,95^{a b}$ & $710,50 \pm 115,90^{\mathrm{b}}$ & 0,0134 \\
\hline Caliciformes ( $\mathrm{n}^{\circ}$ ) & $142,75 \pm 34,55^{a}$ & $146,90 \pm 29,84^{\mathrm{a}}$ & $200,05 \pm 49,54^{b}$ & $<0,0001$ \\
\hline Vilo/Caliciforme & $4,16 \pm 0,91^{a}$ & $4,54 \pm 1,18^{a}$ & $3,79 \pm 1,19^{b}$ & 0,0376 \\
\hline Cripta $(\mu \mathrm{m})$ & $70,34 \pm 21,02$ & $70,58 \pm 16,39$ & $60,63 \pm 19,71$ & NS \\
\hline Vilo/Cripta & $9,10 \pm 3,48^{a}$ & $9,59 \pm 2,74^{a}$ & $12,79 \pm 4,11^{b}$ & 0,0038 \\
\hline Células $\mathrm{CD}^{+}\left(\mathrm{n}^{\circ}\right)$ & $279,90 \pm 116,57^{a b}$ & $329,20 \pm 110,65^{a}$ & $196,10 \pm 69,13^{b}$ & 0,0216 \\
\hline Vilo/CD3 ${ }^{+}$ & $2,32 \pm 0,84^{a}$ & $2,38 \pm 1,15^{a}$ & $3,78 \pm 1,24^{b}$ & 0,0086 \\
\hline \multicolumn{5}{|c|}{$\begin{array}{l}\text { * Composto vegetal - óleo essencial de orégano, alecrim, canela e extrato de pimenta } \\
\text { vermelha. }\end{array}$} \\
\hline
\end{tabular}

avilamicina, ou seja, foi observado uma célula $\mathrm{CD}^{+}$a cada $3,78 \mu \mathrm{m}$ de altura de vilo.

Na avaliação histológica de íleo (Quadro 6), também foi observado altura de vilo significativamente maior no grupo composto vegetal em relação ao controle e avilamicina. Não houve diferença significativa em relação ao número de células caliciformes. Entretanto, observou-se significativa maior relação vilo/células caliciformes no grupo composto vegetal, em que a cada $2,35 \mu \mathrm{m}$ de altura de vilo foi observado uma célula caliciforme. Em relação à profundidade de cripta, foi observado significativa menor profundidade no grupo controle em relação ao grupo composto vegetal. Entretanto, ao realizar a relação vilo/cripta, não foi observada diferença significativa.

$\mathrm{Na}$ avaliação histológica dos cecos, foi observado altura de vilo significativamente maior no grupo controle em relação aos grupos avilamicina e composto vegetal (Quadro 7). Assim como no íleo, o número de células caliciformes também não apresentou diferença significativa entre os tratamentos. Entretanto, observou-se aumento significativo na relação vilo/células caliciformes no grupo controle em relação aos grupos avilamicina e composto vegetal. $\mathrm{Na}$ profundidade de cripta, o grupo controle obteve maior profundidade, seguido pelo grupo composto vegetal, sendo a menor no grupo avilamicina. Na relação vilo/cripta, o grupo avilamicina apresentou proporção significativamente maior quando comparado ao grupo controle. Em relação à imuno-histoquímica (Figura 1), foi observada significativa maior contagem de células $\mathrm{CD}^{+}$no grupo controle em relação ao avilamicina, sendo que o grupo composto vegetal obteve contagem intermediária. Porém, ao ser realizada a relação vilo/células $\mathrm{CD}^{+}$, não foi observada diferença significativa.

Quadro 6. Avaliações em microscopia ótica de fragmentos de íleo de aves de 24 dias de idade inoculadas com $10^{5} \mathrm{UFC}$ Salmonella Enteritidis (Média \pm Desvio Padrão)

\begin{tabular}{lcccc}
\hline \multicolumn{1}{c}{ Variáveis } & Controle & Avilamicina & \multicolumn{2}{c}{ Composto vegetal* Valor de P } \\
\hline Vilosidade $(\mu \mathrm{m})$ & $278,19 \pm 45,22^{\mathrm{a}^{* *}}$ & $249,10 \pm 53,52^{\mathrm{a}}$ & $335,04 \pm 39,95^{\mathrm{b}}$ & $<0,0001$ \\
Caliciformes $\left(\mathrm{n}^{\mathrm{o}}\right)$ & $168,00 \pm 38,11$ & $173,00 \pm 47,43$ & $168,15 \pm 62,06$ & $\mathrm{NS}$ \\
Vilo/Caliciforme & $1,74 \pm 0,517^{\mathrm{a}}$ & $1,55 \pm 0,544^{\mathrm{a}}$ & $2,35 \pm 1,093^{\mathrm{b}}$ & 0,0047 \\
Cripta $(\mu \mathrm{m})$ & $50,89 \pm 11,84^{\mathrm{a}}$ & $57,13 \pm 15,29^{\text {ab }}$ & $66,71 \pm 21,01^{\mathrm{b}}$ & 0,0132 \\
Vilo/Cripta & $5,63 \pm 1,19^{2}$ & $4,71 \pm 1,80$ & $5,53 \pm 1,82$ & $\mathrm{NS}$ \\
* Composto vegetal - óleo essencial de orégano, alecrim, canela e extrato $^{\text {de pimenta vermelha. }}$ \\
** Letras diferentes na mesma linha diferem estatisticamente $(\mathrm{P}<0,05)$. \\
NS: Não diferem estatisticamente $(\mathrm{P}>0,05)$.
\end{tabular}

Quadro 7. Avaliações em microscopia ótica de fragmentos de ceco de aves de 24 dias de idade inoculadas com $10^{5}$ UFC Salmonella Enteritidis (Média \pm Desvio Padrão)

\begin{tabular}{|c|c|c|c|c|}
\hline Variáveis & Controle & Avilamicina & Composto vegetal* & Valor de P \\
\hline Vilosidade $(\mu \mathrm{m})$ & $176,66 \pm 35,10^{a^{* *}}$ & $85,15 \pm 16,0^{b}$ & $98,17 \pm 17,35^{b}$ & $<0,0001$ \\
\hline Caliciformes (no$)$ & $13,65 \pm 8,57$ & $18,0 \pm 11,29$ & $18,0 \pm 7,36$ & NS \\
\hline Vilo/Caliciforme & $17,94 \pm 10,39^{a}$ & $6,09 \pm 3,55^{b}$ & $6,74 \pm 4,09^{b}$ & $<0,0001$ \\
\hline Cripta $(\mu \mathrm{m})$ & $84,98 \pm 22,39^{a}$ & $32,27 \pm 9,38^{b}$ & $45 \pm 11,98^{c}$ & $<0,0001$ \\
\hline Vilo/Cripta & $2,21 \pm 0,7^{a}$ & $2,86 \pm 1,05^{b}$ & $2,34 \pm 0,79 a \mathrm{ab}$ & 0,0489 \\
\hline Células $\mathrm{CD}^{+}\left(\mathrm{n}^{\circ}\right)$ & $63,6 \pm 38,23^{a}$ & $27,7 \pm 19,91^{b}$ & $43,5 \pm 10,82^{a b}$ & 0,0151 \\
\hline Vilo/CD3 ${ }^{+}$ & $3,50 \pm 1,75$ & $3,20 \pm 1,53$ & $2,53 \pm 0,80$ & NS \\
\hline
\end{tabular}

* Composto vegetal - óleo essencial de orégano, alecrim, canela e extrato de pimenta vermelha.

** Letras diferentes na mesma linha diferem estatisticamente $(\mathrm{P}<0,05)$.

NS: Não diferem estatisticamente $(\mathrm{P}>0,05)$.

\section{DISCUSSÃO}

No primeiro experimento o uso de avilamicina e o composto vegetal a base de óleos essenciais de orégano, alecrim, canela e extrato de pimenta na dieta reduziram significativamente os escores de lesões intestinais causados por Eimeria maxima e E. tenella aos 29 dias de idade (14 dias após a inoculação). Vários estudos têm demonstrado que compostos a base de óleos essenciais possuem atividade coccidiostática (Allen et al. 1997, Youn \& Noh 2001, Giannenas et al. 2003, Christaki et al. 2004) ou reduzem o impacto econômico causado pelos coccídios (Ibrir et al. 2002, Duffy et al. 2004, Duffy et al. 2005).

O número e a composição dos microorganismos variam consideravelmente ao longo do trato gastrointestinal. 0 ceco das aves é reconhecido como o segmento de maior colonização de microorganismos, apresentando quantidades que variam entre $10^{10}$ a $10^{12} \mathrm{UFC} / \mathrm{g}$ (Wan der Wielien et al. 2000). Observa-se que a utilização de avilamicina e do composto vegetal reduziram o número de colônias de Clostridium perfringens no ceco das aves, quando comparado ao grupo controle. Estes resultados corroboram com os relatados por Mitsch et al. (2004), onde o uso de óleos essenciais na dieta reduziu a proliferação de Clostridium perfringes no intestino e fezes de frangos de corte, reduzindo o risco de enterite necrótica, assim como Jamroz \& Kamel (2002) também observaram redução significativa no número de Escherichia coli e Clostridium perfringens em ceco de frangos de corte alimentados com mistura de óleos essenciais de capsaicina, cinamaldeído e carvacrol. 


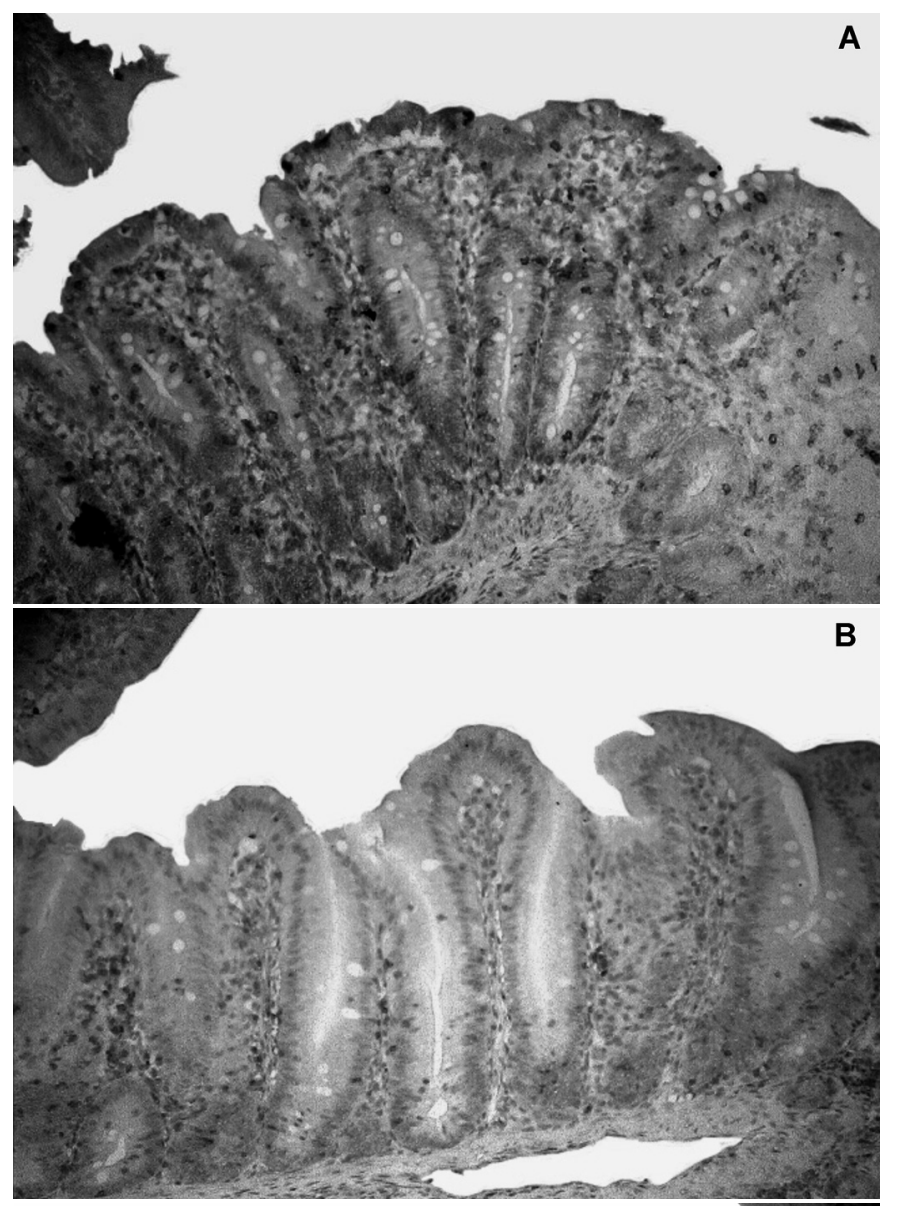

C

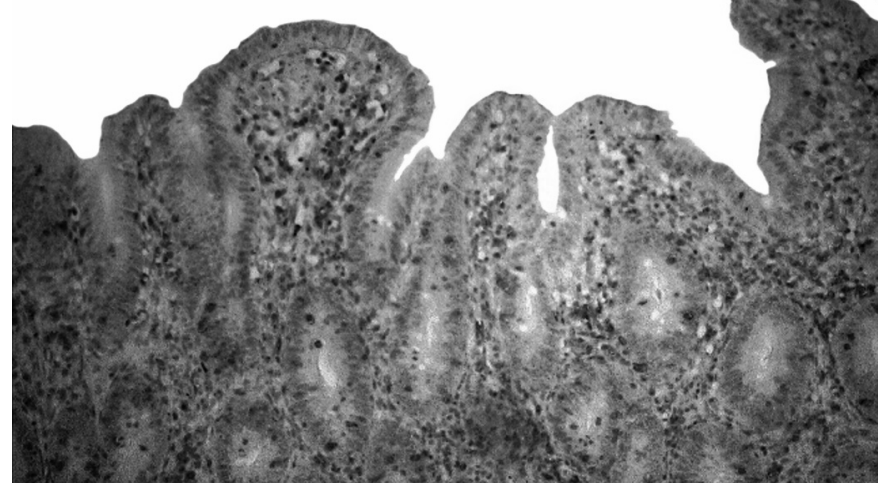

Fig.1. Ceco de frangos de corte aos 24 dias de vida. Marcação positiva de células CD3+ em marron pelo método de imuno-histoquímica. (A) Grupo controle; (B) Avilamicina; (C) Composto vegetal. HE, obj.10x.

A alteração da permeabilidade da membrana das paredes celulares das bactérias se deve ao caráter lipofílico dos óleos essenciais que se acumulam nas membranas. As bactérias gram-negativas possuem uma membrana externa que contém lipopolissacarídeos, formando uma superfície hidrofílica. Este caráter hidrofílico cria uma barreira à permeabilidade das substâncias hidrofóbicas como óleos essenciais, explicando a resistência de bactérias Gram-negativas a esses aditivos (Dorman \& Deans 2000). Sendo Clostridum perfringens uma bactéria Gram-positiva, é pos- sível utilizar compostos a base de óleos essenciais como alternativas para o controle da enterite necrótica em frangos de corte.

Pode-se especular que o controle das lesões causadas por E. tenella tenha interferido na redução da colonização por $C$. perfringens por melhorar a absorção de nutrientes. 0 aumento na digestibilidade e absorção de nutrientes reduzem a disponibilidade de substrato para o desenvolvimento de bactérias patógenas, como por exemplo, Clostridium perfringens (Oetting et al. 2006, Gil de los Santos et al. 2008). Alguns estudos relatam que a inclusão de composto vegetal (orégano, canela e pimenta) na alimentação de frangos de corte melhora o coeficiente de digestibilidade da matéria seca, melhorando o ganho de peso e a conversão alimentar (Jamroz \& Kamel 2002, Hernández et al. 2004). De acordo com Jamroz \& Kamel (2002), o aumento da digestibilidade dos nutrientes devido à suplementação com óleos essenciais favoreceu o equilíbrio da microbiota, diminuindo o potencial de adesão de patógenos ao epitélio intestinal.

Entretanto, alguns autores relatam que uma possível ausência de efeito no desempenho dos animais poderia estar relacionada à composição da dieta basal utilizada e/ou às condições ambientais a que os animais são submetidos (Lee et al. 2003), como por exemplo superlotação (Zhang et al. 2005). Dietas altamente digestíveis limitam o desenvolvimento de bactérias no trato intestinal, pela redução de substrato disponível ao crescimento bacteriano, diminuindo o potencial antimicrobiano dos compostos vegetais. 0 mesmo pode acontecer se os animais forem alojados em instalações com baixo desafio sanitário e com boas condições de higiene e manejo (Lee et al. 2003). Ainda, Barreto et al. (2008) não observaram diferença significativa no desempenho de frangos de corte frente ao uso de óleos essenciais de orégano, cravo, canela e pimenta vermelha utilizados separadamente. Christaki et al. (2004) estudaram o efeito de uma mistura comercial de óleos essenciais em frangos desafiados com Eimeria tenella, e obtiveram resultados positivos com relação ao desempenho (ganho de peso, consumo de ração e conversão alimentar) e observaram redução nas lesões em ceco nos animais tratados com a mistura.

O composto vegetal utilizado neste trabalho pode ser eficiente em controlar lesões causadas por protozoários do gênero Eimeria em aves e também controlar a população de Clostridium perfringens no ceco dos animais. Porém a avilamicina utilizada como APC mostra-se mais eficiente provavelmente devido ao diferente mecanismo de ação, apresentando ação mais imediata, enquanto que os compostos vegetais necessitam de maior tempo para exibir o seu potencial.

No segundo estudo, a contagem de colônias de Salmonella em suabe de cloaca de aves inoculadas com $10^{5} \mathrm{UFC} /$ $\mathrm{mL}$ de SE, nas primeiras 24 horas, demonstrou que o grupo que recebeu avilamicina na dieta apresentou contagem significativamente menor em relação ao grupo controle e ao grupo que recebeu óleo essencial de orégano, alecrim, canela e extrato de pimenta. Estudos de Burt et al. (2007) demonstraram efetividade do vapor de carvacrol, equivalente a $2-4 \mu \mathrm{L}$ de carvacrol puro, na inibição do crescimen- 
to de SE em carcaças de frango. 0 fato deste composto ser puro pode justificar a diferença daquele estudo em relação ao verificado neste trabalho.

Extratos vegetais e seus metabólitos secundários possuem efeito bactericida e bacteriostático dose-dependente sobre o organismo (bactérias, fungos, vírus e protozoários) (Smith-Palmer et al, 1998). 0 mecanismo pelo qual a maioria dos óleos essenciais exerce seu efeito antimicrobiano é por sua atividade na estrutura da parede celular bacteriana, desnaturando e coagulando proteínas (Dorman \& Deans 2000). Segundo estes autores, o rompimento da parede celular ocorre devido ao caráter lipofílico dos óleos essenciais que se acumulam nas membranas.

Apesar de, no presente estudo, os animais que receberam dietas contendo composto vegetal inicialmente $(24 \mathrm{~h}$ após a inoculação) não apresentar diminuição na contagem de Salmonella, porém $72 \mathrm{~h}$ após inoculação observou-se redução na excreção de Salmonella semelhante ao observado no grupo tratado com avilamicina. Bactérias Gram-negativas tendem a ser menos sensíveis aos óleos essenciais e extratos de plantas que as Gram-positivas. Isto porque elas possuem uma superfície hidrofílica, que cria uma barreira à permeabilidade das substâncias hidrofóbicas como os óleos essenciais (Chao et al. 2000). Entretanto, como a maioria das bactérias presentes no intestino das aves são Gram-positivas, os óleos essenciais agem sobre estas e podem permitir que o animal consiga combater bactérias Gram-negativas patogênicas. Desta forma pode-se sugerir o mecanismo do controle sobre excreção de Salmonella evidenciado neste trabalho, que somente ocorreu 72 horas mas não às 24 horas após inoculação.

$\mathrm{Na}$ avaliação histológica de duodeno e íleo, foi observado altura de vilo significativamente maior no grupo tratado com composto vegetal em relação ao controle, sendo similar ao grupo avilamicina no caso do duodeno, o que sugere melhor capacidade absortiva. 0 número de células caliciformes no grupo do composto vegetal foi significativamente maior no duodeno, inclusive em relação ao grupo avilamicina, sendo confirmado pela menor relação vilo/células caliciformes. Essa maior população no número de células caliciformes no grupo tratado com composto vegetal provavelmente induz em maior quantidade de muco e isso pode ser importante para controlar bactérias patogênicas. De acordo com Amit-Romach et al. (2009), a redução na produção de muco possibilita melhores condições de adesão e proliferação de bactérias patogênicas em contrapartida da redução de bactérias benéficas ao organismo.

Ao se observar a relação vilo/cripta, verifica-se maior relação no grupo composto vegetal, no duodeno, sugerindo maior capacidade de renovação celular. Em relação à imuno-histoquímica, foi observado significativo aumento no número de células $\mathrm{CD}^{+}$no grupo que recebeu dieta com avilamicina comparado ao grupo submetido ao composto vegetal. Este resultado sugere menor resposta imune específica nos animais do grupo alimentado com composto vegetal. No ceco o menor número de células $\mathrm{CD}^{+}{ }^{+}$é visto no grupo com avilamicina, porém não existe diferença quando comparamos os resultados de relação vilo/células $\mathrm{CD}^{+}$. Na expressão de células $\mathrm{CD}^{+}$no ceco, sugere-se que a redução no número de contagem de colônias não afeta diretamente a população de células $\mathrm{CD}^{+}$.

Em adição, na histologia de ceco, foi observada altura de vilosidade significativamente maior no grupo controle em relação aos grupos avilamicina e composto vegetal. Em relação à profundidade de cripta, o grupo controle obteve $\mathrm{a}$ maior profundidade, seguido pelo grupo composto vegetal, sendo a menor no grupo avilamicina, indicando possível maior extrusão no vilo, necessitando de maior produção de células pela cripta, o que pode, ainda, estar relacionado a maior quantidade de bactérias isoladas.

\section{CONCLUSÕES}

O composto vegetal a base de óleo essencial de orégano, alecrim, canela e extrato de pimenta vermelha apresentou efeito tanto no controle da colonização por Closztridium perfringens no ceco de aves inoculadas com Eimeria sp., na redução de enterites específicas causadas por Eimeria maxima e E. tenella nas aves 14 dias após a inoculação, quanto diminuindo a excreção de Salmonella em aves 72 horas após a inoculação de $10^{5} \mathrm{UFC} / \mathrm{mL}$ de Salmonella Enteritidis.

A utilização de composto vegetal aumentou a relação vilo/células $\mathrm{CD}^{+}$no duodeno, em relação ao grupo avilamicina e controle, porém não teve efeito sobre a expressão destas células no ceco.

Agradecimentos.- À Grasp Indústria e Comércio Ltda.

\section{REFERÊNCIAS}

Allen P.C., Lydon J. \& Danforth H. 1997. Effects of components of Artemisia annua on coccidia infections in chickens. Poult. Sci. 76:1156-1163.

Amit-Romach E., Uni Z., Cheled S., Berkovich Z. \& Reifen R. 2009. Bacterial population and innate immunity-related genes in rat gastrointestinal tract are altered by vitamin A-deficient diet. J. Nutritional Biochemistry 20:70-77.

Barreto M.S.R., Menten J.F.M., Racanicci A.M.C., Pereira P.W.Z. \& Rizzo P.V. 2008. Plant extracts used as growth promoters in broilers. Braz. J. Poult. Sci. 10:109-115.

Bopp C.A., Brenner F.W., Wells J.G. \& Strockbine N.A. 2003. Escherichia coli, Shigella and Salmonella, p.459-474. In: Murray P.R., Baron E.J., Pfalter M.A., Tenover F.C. \& Yolken R.H. (Eds), Manual of Clinical Microbiology. ASM Press, Washington.

Brasil 2003. MAPA, Instrução Normativa no 6 publicada em 26 de agosto de 2003.

Brasil 2007. Resolução RDC no 2, de 15 de janeiro de 2007. Ministério da Saúde, Agência Nacional de Vigilância Sanitária (Anvisa). Disponível em <http://www.anvisa.gov.br>

Burt A., Fledderman M.J., Haagsman H.P., Knapen F. \& Veldhuizen E.J.A. 2007. Inhibition of Samonella enterica serotype Enteritidis on agar and raw chicken by carvacrol vapour. Int. J. Food Microbiol. 119:346-350.

Butaye P., Devriese L.A. \& Haesebrouck F. 2003. Antimicrobial growth promoters used in animal feed: effects of less well know antibiotics on Grampositive bacteria. Clin. Microbiol. Rev. 16:175-188.

Chao S.C., Young D.G. \& Oberg C.J. 2000. Screening for inhibitory activity of essential oils on selected bacteria, fungi and viruses. J. Essent. Oil Res. 12:639-649.

Christaki E., Florou-Paneri P., Giannenas I., Papazahariadou M., Botsoglou N. \& Spais A.B. 2004. Effect of a mixture of herbal extracts on broiler chickens infected with Eimeria tenella. Anim. Res. 53:137-144.

Costa C.A.F. \& Paiva D.P. 2007. Cultivo in vivo e in vitro e diagnóstico específico de Eimeria spp. Embrapa Suínos e Aves, Concórdia. 102p. 
Desmidt M., Ducatelle R. \& Haesebrouck F. 1998. Serological and Bacteriological observations on experimental infection with Salmonella Hadar in chickens. Vet. Microbiol. 60:259-269.

Dorman H.J.D. \& Deans S.G.2000. Antimicrobial agents from plants: antibacterial activity of plant volatile oil. J. Appl. Microbiol. 83:308-316.

Duffy C.F., Sims M.D. \& Power R.F. 2004. Preliminary evaluation of dietary Natustat ${ }^{\mathrm{TM}}$ versus Histostat ${ }^{\circledR}$ (Nitarsone) for control of Histomonas meleagridis in broiler chickens on infected litter. Int. J. Poult. Sci. 12:753757.

Duffy C.F., Mathis G.F. \& Power R.F. 2005. Effects of Natustat ${ }^{\mathrm{TM}}$ supplementation on performance, feed efficiency and intestinal lesion scores in broiler chickens challenged with Eimeria acervulina, Eimeria maxima and Eimeria tenella. Vet. Parasitol. 130:185-190.

Farmacopea Ufficiale della Republica Italiana 1998. X Edizione. Instituto Poligrafico e Zecco dello Stato, Roma, 1:206-210.

Giannenas I., Florou-Paneri P., Papazahariadou M., Christaki E., Botsoglou N. \& Spais A.B. 2003. Effect of dietary supplementation with oregano essential oil on performance of broilers after experimental infection with Eimeria tenella. Arch. Anim. Nutr. 57:99-106.

Gil de los Santos J.R., Conceição F.R. \& Gil-Turnes C. 2008. Enterite necrótica aviária. Ciência Rural 38:2076-2082.

Hernández F., Madrid J., Garcia V., Orengo J. \& Megias M.D. 2004. Influence of two plant extracts on broilers performance, digestibility, and digestive organ size. Poult. Sci. 83:169-174.

Ibrir F., Greathead H.M.R. \& Forbes J.M. 2002. The effect of thymol/carvacrol treatments on the performance of broiler chickens infected with Eimeria acervulina. Proc. Nutrition Society, London. 61p.

Jamroz D. \& Kamel C. 2002. Plant extracts enhance broiler performance. J. Anim. Sci. 80:1-41.

Johnson J. \& Reid W.M. 1970. Anticoccidial drugs: lesion scoring techniques in battery and floor-pen experiments with chickens. Experim. Parasitol. 28:30-36.

Lee K.W., Everts H. \& Kappert H.J. 2003. Effects of dietary essential oil components on growth performance, digestive enzymes and lipid metabolism in female broiler chickens. Brit. Poult. Sci. 44:450-457.

Lovland A. \& Kaldhusdal M. 2001. Severely impaired production performance in broiler flocks with high incidence of Clostridium perfringens-associated hepatitis. Avian Pathol. 30:73-81.
Luna L.G. 1968. Manual of histologic staining methods of the army force Institute of Pathology. $3^{\text {rd }}$ ed. McGraw-Hill, New York. p.32-46.

Maiorka A., Santin E., Silva A.V.F., Bruno L.D.G., Boleli I.C. \& Macari M. 2000. Desenvolvimento do Trato Gastrointestinal de Embriões Oriundos de Matrizes Pesadas de 30 e 60 Semanas de Idade. Revta Bras. Ciênc. Avícola 2:141-148.

McDougald L.R. 1998. Intestinal protozoa important to poultry. Poult. Sci. 77:1156-1158.

Mitsch P., Zitterl-Eglseer K., Köhler B., Gabler C., Losa R. \& Zimpernik I. 2004. The effect of two different blends of essential oil components on the proliferation of Clostridium perfringens in the intestines of broiler chickens. Poult. Sci. 83:669-675.

National Research Council. 1994. Nutrient requirements of poultry. $9^{\text {th }} \mathrm{ed}$. National Academy Press, Washington, D.C.

Oetting L.L., Utiyama C.E., Giani P.A., Ruiz U.S. \& Miyada V.S. 2006. Efeitos de extratos vegetais e antimicrobianos sobre a digestibilidade aparente, o desempenho, a morfometria dos órgãos e a histologia intestinal de leitões recém-desmamados. Revta Bras. Zootec. 35:1389-1397.

Saad M.B. 2009. Efeito da suplementação de selênio orgânico na resposta imunológica de frangos de corte. Curitiba. Dissertação de Mestrado em Ciências Veterinárias, Curso de Pós-Graduação em Ciências Veterinárias, Universidade Federal do Paraná. 53p.

Barnes H.J. 2008. Clostridial disease, p.865-890. In: Saif Y.M. (Ed.), Diseases of Poultry. $12^{\text {th }}$ ed. Iowa State University, Ames.

Simões C.M.O. \& Spitzer V. 1999. Óleos voláteis, p.387-416. In: Simões C.M.O., Schenkel E.P., Gosmann G., Mentz L.A. \& Petrovick P.R. (Eds), Farmacognosia: da planta ao medicamento. UFRGS, Porto Alegre.

Smith-Palmer A., Stewart J. \& Fyfe L. 1998. Antimicrobial properties of plant essential oils essences against five important food-borne pathogens. Lett. Appl. Microbiol. 26:118-122.

Van Der Wielen P.W., Biesterveld S., Notermans S., Hofstra H., Urlings B.A.P. \& Van-Knapen F. 2000. Role of volatile fatty acids in development of the cecal microflora in broiler chickens during growth. Appl. Environ. Microbiol., 66:2536-2540.

Youn H.J. \& Noh J.W. 2001. Screening of the anticoccidial effects of herb extracts against Eimeria tenella. Vet. Parasitol. 96:257-263.

Zhang K.Y., Yan F., Keen C.A. \& Waldroup P.W. 2005. Evaluation of microencapsulated essential oils and organic acids in diets for broiler chickens. Internat. J. Poult. Sci. 4:612-619. 